\title{
"FESTAS" Y "DESAFÍOS" EN UNA \\ COMARCA RURAL DEL SUR DE GALICIA: \\ SOLIDARIDADES Y RIVALIDADES \\ POÉTICO-FESTIVAS EN LA \\ REPRESENTACIÓN SIMBÓLICA DE DOS \\ NIVELES DE IDENTIDAD \\ COMUNITARIO-VECINAL
}

\author{
por \\ ENRIQUE COUCEIRO DOMÍNGUEZ
}

Este estudio trata de ser una reflexión en torno a determinados aspectos estructurales de diversas configuraciones festivo-ceremoniales y poético-verbales propias de unas comunidades vecinales del Sur de Galicia, en cuanto que tales configuraciones constituyen modos de representar y formalizar simbólicamente la identidad comunitaria de los colectivos que en ellas participan y, en particular, la de aquellos que actúan como organizadores y anfitriones de cada ocasión festiva.

Las descripciones etnográficas sobre cinco diferentes celebraciones festivas, punto de partida de los elementos de reflexión antropológica, están tomados de las notas recogidas durante la investigación de campo desarrollada, desde 1985 en la parroquia de Entienza y feligresías adyacentes, situadas entre las comarcas de El Condado y Bajo Miño, al sur de la provincia de Pontevedra, y en las inmediaciones de la frontera internacional entre España y Portugal. 
Es una zona rural que basa sus sistema de producción en una tradicional estrategia de simbiosis agro-ganadera de concepción autárquica —en la cual la "casa" representa la unidad clave de explotación y autoconsumo de lo producido en régimen de subsistencia-complementada hoy con los imprescindibles recursos monetarios obtenidos en el ejercicio de empleos remunerados (cantería, construcción e industria).

La estructura e interacción sociales siempre se han apoyado en tres niveles socio-espaciales de agrupamiento: la "casa", el "lugar" y la "parroquia". Estos dos últimos constituyen niveles clave de la organización comunitaria intervecinal, por más que sea la "casa" la unidad familiar, el eje fundamental sobre el que pivota el sistema de relaciones sociales, el "ethos" y la "Weltanschauung" tradicionales. Sin embargo, será sobre los "lugares" y "parroquias": "parroquias" donde vamos a centrar nuestra atención en esta reflexión:

- Los "lugares" o "barrios" constituyen segmentos poblacionalterritoriales de pequeña magnitud (no suelen superar el centenar de habitantes), aunque representan núcleos específicamente significativos por los intensos vínculos de cohesión - y también, en ocasiones, de gran rivalidad-que ligan a sus "veciños" miembros.

- Las "parroquias" son las grandes unidades socio-territoriales de identidad comunitaria. Múltiples son los vínculos que confieren una solidez excepcional a las relaciones entre "veciños da parroquia". Las parroquias de la zona no suelen superar el millar de habitantes, pero cada una subsume dentro de sus límites un elevado número de "lugares" o "barrios". Así, Entienza, de 710 habitantes, engloba un total de 20 "barrios", con una población que varía entre 6 y 108 vecinos.

En este contexto socio-económico tan a grandes líneas bosquejado, se celebran las "festas" que a continuación paso a describir en sus aspectos fundamentales:

A) "Festas" y "romarías" de "barrio" o "lugar".

* La Asunción en el "barrio" de Asunción (Entienza). Celebrado el día 15 de agosto, en plena temporada festiva estival, el "Día Santo" comenzaba con la "alborada" - alegre aire de gaitas y "pandeiros"- que, discurriendo por caminos de la parroquia, marca el inicio de los festejos. Para la Misa Mayor de la mañana, los vecinos de Entienza, en conjunto, subían procesionalmente el camino que une la céntrica iglesia parroquial al "barrio" y capilla de Asunción, situados al Oeste. Portaban en "angarillas" la imagen de la "Virgen Nova". Al llegar frente al "turreiro" explanada de congregación vecinal con la que cuenta cada "lugar", situada al lado de capillas o iglesias parroquiales y escenario tradicional de las "festas" vespertinas- de la Asunción, ante la capilla, los "veciños" de este "lugar" salían al paso de la procesión ascendente encabezados por la

"CUADERNOS DE ESTUDIOS GALLEGOS", Tomo XXXIX, Fascículo 104, Santiago 1991 
imagen de la "Virgen Vella da Asunción", portada igualmente en "angarillas". Entonces tenía lugar la ceremonia de "as venias" - salutaciones y muestras de respeto rituales - en la que los portadores de sendas imágenes, encarados unos frente a otros, las inclinaban hacia adelante, en intercambio de reverencias y homenajes recíprocos. "As venias" constituían un auténtico rito de paso e integración: A cada inclinación, la "Virgen Vella" retrocedía un paso hacia las puertas de la capilla, y la "Virgen Nova" iba avanzando. Tres eran estas "venias". Tras la ceremonia, ambas imágenes, ambos vecindarios, se unían en procesión alrededor de la capilla, junto con las representaciones procesionales que habían acudido de siete parroquias vecinas (Soutelo, Parderrubias, Salceda y otras), y ante las que se había repetido la ceremonia de "as venias". Después comenzaba la Misa Mayor. A la tarde se celebraba "o baile" o "as festas" con la concurrencia de propios y extraños al "turreiro" flanqueado por "postos" de "rosquilleiras" y de bebidas ("carros" y "chafaricos"), y amenizado por música de gaitas y fuegos artificiales.

* San Blas en Pedracarballa (Entienza). San Blas es un Santo de gran devoción en la región. Son multitud los creyentes que formulan "promesas" en momentos críticos de la vida, considerándole un "Santo moi abogoso", en especial como intercesor místico para la curación de las enfermedades de garganta. Por ello, la "festa" de San Blas, celebrada el 3 de febrero, es muy concurrida por devotos de las parroquias comarcales que acuden para "cumplir" la "promesa" una vez elevada al Santo, por cuya "man" se cree haber recuperado la salud. Son los "ofrecidos".

Las ceremonias religiosas ("cumprimentos", Misa Mayor y bendición de panes) tenía lugar por la mañana. Por la tarde, el "turreiro" se transformaba en el profano escenario de las "festas". Grandes "bombas", "retretas" y demás fuegos de artificio coronaban el cielo nocturno de un "lugar" que, esa noche del año, se convertía en centro del cosmos. Acudían grupos de "veciños" de múltiples parroquias cercanas. Música de gaiteros o de bandas municipales - hoy de conjuntos juveniles - en el "palco" festivo ensamblado de maderos. Baile de jóvenes - los verdaderos protagonistas - al caer la noche. Abundante charla y libaciones en los "postos" de bebidas. A veces el "viño" o la disputa por una muchacha desencadenaban las "pelexas" juveniles, reyertas multitudinarias en las que terminaban involucrándose grupos enteros de jóvenes que acudían en apoyo solidario de sus convecinos frente a los de otra parroquia. Estas "pelexas" son más raras hoy en día, pero antaño fueron muy frecuentes.

Hay que señalar el hecho de que los "veciños" de este lugar de Pedracarballa han mantenido una pacífica rivalidad poético-festiva con los del "barrio" de Asunción, también situado en la parroquia de Entienza, aun- 
que a $2 \mathrm{kms}$. de distancia. Esta rivalidad se nutría del hecho de que ambos vecindarios han descollado tradicionalmente por su cohesión interna, volumen poblacional y dinamismo festivo, centrado alrededor de sendas capillas.

Un ejemplo de "desafío" poético dedicado satíricamente por los "veciños" de San Blas a los de Asunción es el siguiente:

"Catro canas, non son canas./ Catro canas, canas son./

Catro cudichos de Entienza / van á festa da Asunción".

"Cudichos" es el término que peyorativamente asignan vecinos de otras parroquias a los de Entienza. Alude a la costumbre de aprovechar hasta las cortezas de pan de maíz (alimento ínfimo) que se les imputa.

* Los "Entruidos" de Castro Barreiro y Feira (Salceda). Los Carnavales de Salceda se celebran —en proliferación de fuegos artificiales, máscaras de "entruidos" o "mamarrachos" y rivalidad festiva interlocal- durante la noche del "Luns de Entruidos" y el Martes de Carnaval. Los "barrios" vecinos de Castro Barreiro y A Feira preparan desde meses antes sendos y rivales "Entruidos" o fiestas de Carnaval, que celebrarán paralelamente la misma noche del lunes en sus respectivos "turreiros". Son "festas" vividas en exlplícito e intensísimo clima de rivalidad vecinal y que, por su gran popularidad, llegan a congregar miles de visitantes.

La competencia es previa, incluso, al propio día de los festejos. Cada "barrio" prepara sus espectáculos (carrozas vistosamente ornamentadas que se exhibirán en competición de comparsas el Martes de Carnaval; conjuntos de comparsas danzantes; "desafíos" satíricos versificados que se intercambiarán en el apogeo de la "festa"; fuegos artificiales, etc.), procurando en todo momento que los "veciños" del "barrio" opuesto no puedan hacerse idea de tales preparativos. Incluso en la escuela, los niños de uno y otro "lugar" dejan de hablarse; la rivalidad, aún latente en las vísperas, es palpablemente intensa.

En la noche de fiestas, desde cada "turreiro" se lanzan "retretas", "bombas" y otros costosos cohetes, en alarde de esplendor y competición de vistosidad. Se entrecruzan "desafíos" amplificados por altavoces. Se rivaliza en la popularidad de los conjuntos musicales contratados... Propios y extraños ponderan y comparan la brillantez de ambas celebraciones. Casi todos los asistentes van enmascarados y, permanentemente, alternan entre uno y otro "barrio", entre ambos "turreiros", subiendo y bajando por un oscuro "camiño" que media entre los dos. Si los forasteros saben que, esa noche, los dos vecindarios "se levan a matar", en realidad todos reconocen que el atractivo de "a festa" - tácitamente una sola, por interdependencia - se encuentra precisamente en el contínuo alternar en un ambiente de rivalidad lúdica y desenfadada que a todo caracteriza, 
que todo lo penetra. Por el oscuro camino, y en dirección a su propio "barrio", vecinos enmascarados de uno y otro "lugar" van aconsejando a quienes transitan en sentido opuesto que vuelvan atrás, que "a festa" en el "turreiro" rival "non val nada".

Es noche de licencias carnavalescas; cada cual da rienda suelta a sus impulsos emocionales escondiendo su personalidad cotidiana tras la máscara de "entruido". Paradójicamente, gracias a la rivalidad la "festa" se hace una para los asistentes. Una, pero magnificada, singularmente realzada por la oposición interlocal que la estructura. Algunos ejemplos de "desafíos" propios de "Entruidos", sarcasmos en los que se utilizan anécdotas risibles, son los siguientes:

- "Os furiños da Feira / ó Barreiro viñeron asexar,

e como nada miraban / con auga os tivemos que lavar".

- "O Xan do Medio pra un gaiteiro darlle de cenar /

a taberneira ben que o tivo que avergonzar".

- "O Papón anda amargado /

porque o Carnaval da Feira anda acabado".

B) "Festas" y "romarías" parroquiales" Las "venias".

* "Romaría" de San Cibrián en Guláns. Celebrada el 16 de septiembre en una capilla situada en lo alto del monte de San Cibrián, al que da nombre, la "Romaría" de San Cibrián congregaba en otros tiempos hasta catorce parroquias de los entornos, número hoy más reducido. El ascenso procesional se realizaba siguiendo dos rutas diferentes, establecidas en función de las respectivas situaciones de las parroquias en torno al monte. Antes del inicio del ascenso, las procesiones de cada vecindario (en este caso las que acudían desde el sur) confluían en una "carballeira" situada a pie de vía, en la parroquia de Picoña, portando sus "pondóns" o estandartes parroquiales y las "imaxes" de sus "Santos" representativos. Era allí donde se saludaban, en rito de alianza y recíproco homenaje, con la ceremonia de "as venias": Reverencias mútuas inclinando imágenes y "podóns".

Tras las "venias", cada parroquia comenzaba a ascender siguiendo el orden que tradicionalmente le corresponde. En determinados puntos del camino la procesión hacía paradas generales para efectuar salutaciones rituales a cinco santuarios situados en cumbres que se divisan en la lejanía. Al llegar a la cima donde se encuentra la capilla, culminaba la procesión realizando "venias" ante la imagen de San Cibrián, sacada al paso por los vecinos de Guláns, parroquia dentro de cuyos límites se encuentra el santuario.

Después de la Misa continuaba la "romaría" durante el día y la noche: Todos llevaban la comida, el "viño" y la empanada. Al bajar, alegres de 
"viño" y conversación, cada cual se unía - tiempo ya de carácter profano- de "leria" (de charla) con quien quisiese.

* "Festas" de San Roque en Arantey. San Roque es "Santo" que arrastra una multitudinaria devoción en toda la comarca; a su procesión y "festas" acuden muchos "ofrecidos" con ánimo de "cumplir promesas" que una vez le hicieran, ya que se le considera "un Santo moi abogoso prás enfermedades".

Lo que más interesa describir de estas "festas" es una práctica ceremonial hoy casi olvidada: el "recebemento" colectivo que los "veciños" de Arantey dispensaban a los de Entienza, parroquias limitadas por el río Caselas que, desde siempre, han mantenido unos vínculos de particular buena avenencia.

El día de San Roque, los vecinos de Entienza se reunían en el "turreiro" del "barrio" de Cruceiro, vestidos con sus mejores ropas festivas. Desde allí se encaminaban al río "de romaría" con júbilo y alegría exteriorizados por la música de gaitas, "pandeiros" y "cunchas". Cruzaban el río limítrofe y, ya entrando en el "lugar" donde se encuentra la iglesia de la vecina parroquia, dedicaban la música de sus gaitas a la comunidad anfitriona. Ésta, por su parte, les salía al paso encabezada por el cura párroco, y les daba su "recebemento" su ceremonial y hospitalaria aquiescencia a que estos forasteros compartiesen sus "festas", devolviendo cortésmente el musical saludo recibido con la música de alguna banda contratada para amenizar el "baile". A continuación, continuaba el "recebemento" convidando a los recién llegados a "tomar un viño". Ya a la noche, comenzaba "o baile" en espíritu de diversión y jolgorio generales, tras el hermanamiento interparroquial.

\section{REFLEXIÓN}

Múltiples y heterogéneos son los tópicos que designan a las diferentes facetas de la identidad. La identidad grupal se nos muestra como esencialmente heterotópica, polimórfica, proteica, variable por la pluralidad de referencias y modos de expresión que la generan significándola ${ }^{1}$. Aquí nos centramos fundamentalmente en el modo festivo de designación y exaltación de dos referentes tópicos privilegiados en la cultura gallega; dos referentes socio-espaciales: La "parroquia" y el "lugar". Muchos más son los diferentes tópicos (la "familia" o "casa", el grupo de parentesco, el grupo de amigos o "compañeiros", el tipo de oficio que se desempeña, el pertenecer o no a asociaciones vecinales de carácter voluntario, los gentilicios más o menos peyorativos con los que son conocidos los vecinos de una

${ }^{1}$ Estas características esenciales de la identidad cultural las expresa Carmelo Lisón Tolosana en "Antropología Social y Hermenéutica". Madrid, 1983; Págs. 148149. 
parroquia por vecindarios limítrofes). Todos ellos disciernen y representan mismidad y otreidad grupales. Y unos, con respecto a otros, son más o menos inclusivos o exclusivos; extienden o restringen su capacidad de identificación a más o menos individuos y/o grupos. La identidad, desde su carácter heterotópico, es politómica: podemos buscar su huella en variadas formas que parcialmente la significan. Pero es politómica, también, en el sentido de que algunos de los tópicos que la significan quedan sistemáticamente e idealmente subsumidos en, y la discontinuidad que generan culturalmente superada por otros más globalizadores. Este sentido de indentidad politómica podemos observarlo con claridad en los referentes socio-espaciales de la identidad comunitaria: Ser "veciño" en una comunidad territorialmente delimitada (el espacio y sus límites constituyen, quizá, la metáfora más general y eficaz a la hora de idear la mismidad/otreidad grupales), puede denotar alternativamente dos disímiles estratos de identidad: la pertenencia a la "parroquia", más inclusiva y extensa, o al "lugar", más exclusiva y restrictiva, y subordinada a la primera. En la delimitación y exaltación anímica de estos dos niveles de identidad es donde las celebraciones festivas colectivas operan como modos aventajados de expresión, por cuanto exteriorizan, proclaman y formalizan con intensidad simbólica los ámbitos y relaciones de vecindad, de "ser veciños".

"Parroquia" y "lugar" dan forma conceptual, instilan existencia significativa, funcional - no substancial — a la identidad comunitario vecinal. La importancia del estudio de las celebraciones festivo-ceremoniales comunitarias y ritos y fórmulas poéticas ligados a las mismas, radica en que por convergente simbolización enfocan, ilustran y generan aquellos dos referentes tópicos, "rostros" clave de la identidad grupal en esta comarca del sur de Galicia.

Por delimitar simbólicamente, por fabricar la discontinuidad especificadora de grupos, y por conferir su existencia relacional a las identidades grupales, las "festas", "desafíos" y actos ritual-ceremoniales asociados, pueden considerarse estrategias comunicativas y dialécticas, "modos" particularmente eficaces de generación o eclipsamiento de las fronteras ideales que dan variable consistencia formal al trinomio "nosotros/ vosotros/ellos". Tales términos sólo existen como extremos interdependientes de una relación funcional ${ }^{2}$. Contínuamente observamos la contingencia de la identidad en cada tópico; que ésta no es substancial, omnioperativa en cualquier contexto o momento. El "nosotros" depende alternativamente de los disímiles tópicos que lo califican en función del contexto pertinente. Pero de igual manera, y simultáneamente, variarán los tópicos que dan forma al "vosotros" y al "ellos" grupal. Y es a través de

${ }^{2}$ Cf. Ernst Cassirer "Las Ciencias de la Cultura". 1942; Págs. 80-87 de la 2 $2^{\underline{a}}$ ed. en español, en F.C.E., 1955.

"CUADERNOS DE ESTUDIOS GALLEGOS", Tomo XXXIX, Fascículo 104, Santiago 1991 
la escenificación, de la manifestación de la relación tópica que cualifica al "nosotros" y al "vosotros", como las ceremonias y ritos festivos consiguen generar y subrayar la existencia de estos últimos. Las fiestas plantean diversos modos de relación dialéctica, de integración/separación grupales. Es la percepción de esta relación la que permite al "nosotros"/ "vosotros" reconocerse, generarse cognitivamente. Estos términos de identidad se construyen por unificación y oposición; tales procesos permiten imaginar fronteras, posiciones espaciales disímiles que sugieren figuradamente dispar identidad grupal. Y para ilustrar tal relación, para acotar los perfiles de la especificación, en las "festas" convergen varios procedimientos expresivos: "Recebementos" y "venias", como escenificaciones ceremoniales de reducción de barreras intergrupales tras la delimitación de las distintas identidades de los colectivos participantes; rivalidades visuales (competición entre fuegos artificiales); antagonismos musicales (caso de los Carnavales de Salceda); intercambios musicales que connotan la intención de buscar el acercamiento y la alianza interparroquiales ("recebementos" de San Roque); rivalidades poéticas entre "lugares" (los "desafíos") y, fuera ya de las formas codificadas, ceremoniales, rituales o poéticas, las mismas "pelexas" violentas que convierten la alteridad grupal en un abismo insalvable.

Por otra parte, cada celebración festiva constituye un modo especializado de formalización y exaltación simbólica de cierto nivel o estrato particular de especificidad comunitaria. Cada tipo de "festa" es como un texto escenificado que dramatiza, proclama, cierto nivel de ipseidad comunitaria con preferencia a otros, a los que coloca en segundo plano, implicándolos indirectamente o eclipsándolos, superándolos. Así, las "festas de lugar" (Asunción, San Blas, "Os Entruidos"), magnifican, dan relieve prevaletne al "barrio" contraponiéndolo al resto de vecindarios de igual rango dentro de la misma parroquia (casos de San Blas en Pedracarballa, o Asunción), o bien oponiéndose a uno sólo de los restantes "lugares" en concreto ("Entruidos" de Castro Barreiro y A Feira). En cualquier caso, se trata de distanciar o confrontar estructuralmente, de introducir discontinuidad entre grupos, para reconocer mismidades propias y ajenas a partir de tal disociación.

La identidad diferencial de los vecindarios de "lugar" queda eclipsada, superada en otros contextos festivos (San Roque de Arantey; "Romaría" de San Cibrián) donde no es pertinente su definición. Por el contrario, en las respectivas "festas de lugar", sólo se puede enfatizar la diferencia específica de los "barrios" relegando a un segundo y tácito plano la común pertenencia al estrato superior que engloba a aquellos como subsegmentos, y los une en un contínuo cuyos referentes tópicos son "a parroquia" y "os veciños da parroquia". 
Por ello, en las "festas de lugar" predominan formas de relación ceremonial o poética caracterizada por la rivalidad, por el 'distanciamiento' ideal, expresado por contraposición y antagonismo pautados, entre colectivos que, así, se perfilan como "barrios" ("Entruidos"; "desfíos" entre San Blas/Asunción-Entienza), aunque también existan formas ceremoniales que subrayan, en primer lugar, la distancia entre "barrios" sólo para, a renglón seguido, proceder a la unificación o alianza entre los mismos por la expresión ritual del recíproco respeto. Estas últimas formas, similares a las ceremonias de homenaje interparroquial, están característicamente marcadas por el predominio de componentes sacro-religiosos; es el caso de la primera fase de la procesión a la capilla de Ascensión en Entienza, cuando los "veciños" del "barrio" intercambian "venias" con los del resto de la "parroquia".

En todas estas "festas de barrio" se relega a un segundo plano el referente socio-espacial más inclusivo de la identidad comunitaria: la "parroquia". Sin embargo, tal referente tópico no deja de operar tácitamente: la rivalidad y oposición poéticas y festivas entre "lugares" sólo puede llevarse a cabo - y en tales formas codificadas, pautadas - porque todos los "barrios" antagonistas parten del tácito reconocimiento de la común adscripción a un estrato parroquial superior y que a todos engloba dentro de un 'totuum' supra-local.

Este tácito reconocimiento de la comunidad parroquial se encuentra implícito en el hecho de que sólo entre vecindarios de "lugar" pertenecientes a una misma parroquia se desarrollen rivalidades festivas y poéticoverbales de carácter ludrico. Existe otros 'rastros' que también nos indican que, aún tácitamente, los vínculos de convecinidad parroquial no dejan de operar incluso tras la prevalente intención de resaltar las identidades vecinales de "lugar". En mayor o menor medida, vecinos de toda la parroquia aportan para sufragar los gastos de las "festas" de un "lugar"; asociaciones de vecinos de ámbito parroquial se encargan del "arranxo" o arreglo y financiación de tales "festas"; cuando surge una seria disputa festiva entre grupillos de "veciños" y "xente de fora", vecinos de cualquier rincón del territorio parroquial acuden resueltamente en apoyo de los 'suyos'. Esta solidaridad de fondo que impregna el contexto y los momentos críticos de las "festas de lugar" nos indica que éstas no sólo son modos de representar por rivalidad los límites simbólicos de la identidad de cada "barrio", sino, simultanea y tácitamente, formas de expresión indirecta de la "parroquia", un referente global de identidad que actúa subsumiendo sistemáticamente, y en última instancia, las identidades de niveles que constituyen sus segmentos. Si las "festas de lugar" son, directamente, formas de expresión que dotan de relieve y especificidad al "lugar" que las celebra, precisamente a partir de la formalización principal 
de los límites de la 'parte' —el "lugar" - también constituyen modos indirectos de definición y ponderación del 'todo' que engloba a aquella: la parroquia. Así, dicho de otra forma, las "festas de lugar" configuran al segmento socio-espacial que las celebra como sinécdoque expresiva del 'todo' parroquial que le engloba.

Las celebraciones festivo-ceremoniales resumen el cosmos de las identidades comunitarias, lo sacan a la luz de la conciencia transformando el "turreiro" vecinal en sinopsis escenificada de tal cosmos, en el cual los actores - "veciños" y "xente de fora" - se representan. Las identidades se reconocen y reconstruyen cuando los participantes entran en una comunicación festivo-cermonialmente codificada en la que son tanto actores como espectadores. Pero en virtud de la misma comunicación escenificada, el "nosotros" y el "vosotros" no se limitan a reconocerse, sino a valorarse, ya que la relación dialéctica de reintegración/separación se expresa en forma de procesos de solidaridad/rivalidad grupales. Paralelamente a un sistema cognitivo de la identidad grupal se diseña un sistema moral, perfilado por el contraste entre solidaridades vecinales y rivalidades intergrupales. Confluyen en la "festa" el 'ser' y el 'deber ser'. Es más, el 'ser' (la mismidad/otreidad) sólo puede concebirse desde el 'deber ser' ético (solidaridad/rivalidad o respeto recíproco) y viceversa.

En los "Entruidos" simultáneos de los "lugares" de Castro Barreiro y Feira, ambos vecindarios 'olvidan' temporalmente los muchos lazos de parentesco o amistad que pueden ligarles con habitantes del "lugar" contrario. Destacan así, y festejan para uno sólo de los niveles expresivos de la identidad grupal; el vecindario de "lugar". Y manifiestan cabalmente su solidaridad "lugareña" de diversas formas (ocultando verbal y físicamente los preparativos festivos, arreglando 'sus' comparsas y carroza, actuando como un sólo bloque - solidaridad y cohesión extremas - durante las manifestaciones de rivaliad ceremonial y poética). Los "desafíos", a pesar de que hagan satírica alusión a individuos concretos, vecinos del "barrio" opuesto, en realidad su intención no es la de zaherir personalmente, sino la de burlar, satirizar a la comunidad opuesta en su conjunto. Los "desafíos" constituyen, así, formas metafóricas de competencia y rivalidad festiva entre "lugares" y sólo entre "lugares". Pero tales "desafíos" se han de realizar en código poético, con rima y medida, con pauta y regla; y sólo "desafíos" igualmente codificados pueden darles réplica. Si la rivalidad festiva interlocal es simultánea a una solidaridad intralocal puesta de relieve, el hecho de que los "desafíos" sean pautas codificadas, reglamentadas de rivalidad connota un precepto ético más profundo: Toda rivalidad 'real', no figurada; toda enemistad visceral, marcada por la violencia recíproca entre "lugares" pertenecientes a una misma "parroquia" es moralmente reprobable y objeto de proscripción. La rivalidad no ha de reflejar- 
se en el cristal de una enemistad exacerbada, sino en un antagonismo ritualizado, una competencia fingida que implica, en definitiva, la catársis y negación de enemistades grupales disgregativas entre "lugares" de una misma "parroquia". El "lugar" está (cognitivamente) y ha de estar (moralmente) supeditado a la "parroquia". Sólo desde la reintegración previa y tácita en un superior y englobante nivel de identidad comunitaria es posible, ética y cognitivamente, marcar límites, discontinuidades, imagina y representa simbólicamente la diversidad de especificidades de "lugar".

Si enfocamos ahora el diferente planteamiento estructural de las "festas" y ceremonias interparroquiales, que superan en todos los casos la matización de especificidades de "lugar", observamos que en ellas, a diferencia de las "festas de lugar" predominan ritos y ceremonias de carácter integrativo, aproximativo y expresivos de respeto mútuo centrados en torno al intercambio simbólico entre vecindarios de "parroquia".

Es a través de este intercambio protocolario de expresiones y símbolos de armonía, respeto mútuo y entendimiento ("venias" y "recebementos" con música y vino) como se posibilita la participación conjunta interparroquial, la sinergia de la ceremonia religioso-procesional y de la "festa" nocturna ligada a ésta. Este mensaje escenificado, inicial, de respeto y valoración mutuos es primordial, básico para el discurso concordante de las celebraciones interparroquiales, para que éstas no se troquen en desacreditaciones o, incluso, batallas entre vecindarios. En este tipo de celebraciones no sale a relucir ningún tipo de estrecho vínculo moral de solidaridad entre parroquias: tal vínculo es inexistente desde el momento en que no existe vecindad supra-parroquial. Tanto es así que, incluso perteneciendo dos personas a un mismo municipio - unidad administrativa que no ha alcanzado en Galicia especial significación cultural como ámbito referente de identidad comunitaria—, no se consideran "veciños" entre sí, no siendo que simultaneamente pertenezcan a una de las parroquias que abarca tal unidad administrativa. Y no considerándose "veciños", las relaciones interparroquiales que se establezcan en las procesiones y "festas" dejan de estar condicionadas por el componente ético inherente a las relaciones intervecinales: el principio de solidaridad.

Los límites de las especificidades parroquiales son insalvables en términos de 'vecindad' y 'solidaridad vecinal'. Es más, los confines simbólicos de las distintas mismidades grupales se remarcan desde el primer momento. En "Recebementos" y "venias" observamos que los vecindarios parroquiales se encaran entre sí como unidades diametralmente opuestas. Queda visualmente patentizado quién es quién. Pero, simultaneamente, tal oposición posibilita el intercambio, el inicio simbólico de una relación de integración en un todo festivo voluntariamente buscada. Es el intercambio el medio, el puente que reduce la extrema 'distancia de identi- 
dad entre los dos polos. Intercambio de "venias", de reverencias, de música y vino, que simboliza reciprocidad de reconocimiento, de respeto hacia la alteridad del otro grupo. Un reconocimiento de que ningún "Santo" y ninguna parroquia de la cuál aquél es patrón-emblema místico, predominan sobre ningún "Santo" e identidad comunitaria ajenas. Es más, no pudiéndose establecer el vínculo intergrupal, en estas celebraciones, por el reconocimiento tácito de la vecindad y su solidaridad pareja, se genera simbólicamente por otra vía: por la sacralización de los límites de las respectivas identidades y la imaginación de un vínculo místico entre las mismas. 'Sobre las parroquias, sólo la Divinidad'. De ahí las "venias" o reverencias rituales entre imágenes de "Santos" en la romería procesional a San Cibrián o en el momento en que la parroquia de Entienza, unificada ceremonialmente con 'su' "barrio de Asunción", recibe a las formaciones procesionales que acuden de parroquias cercanas. Los "recebementos" de Arantey a Entienza no están caracterizados por la sacralidad, pero el respeto y reconocimiento mutuo siguen estableciéndose por vía de un excepcional intercambio de música, vino y alegría. Por estos intercambios simbólico-rituales se reduce la radical distancia de identidad entre parroquias, y así puede darse la participación entre colectivos dentro de una misma celebración. Pero los límites de la especificidad parroquial no por ello quedan eclipsados sino relegados a un plano secundario dentro - y sólo dentro- de la celebración total. Sea como sea, latente o explícitamente, la solidaridad entre "veciños de parroquia" y la oposición interparroquial permanecen operativas en cualquier contexto festivo. La co-participación colectiva de carácter armónico sólo queda garantizada por la solemnidad de las ceremonias de alianza ("venias" y "recebementos") fuertemente ritualizadas, que se han dado por la mañana. Pero tal solemnidad se relaja hasta casi desaparecer durante el "baile" o "festa" vespertina, contrapunto profano del día. Es entonces cuando una transgresión - una riña por muchachas; un roce entre jóvenes enardecidos por el vino- puede destruir la sutil regla del respeto mutuo interparroquial, dejando su endeblez al descubierto. A veces estallaban violentas "pelexas" entre "veciños" y "xente de fora" cuando la solidaridad vecinal, saliendo bruscamente a la superficie, movía a unos y a otros a cerrar activamente filas alrededor de los suyos. Esta eventual rivalidad violenta entre "veciños" de diferentes parroquias llegaba a ser tan usual en otros tiempos que ha cristalizado en el refranero popular: "Ó que vai á festa, pódenlle rompe-la testa". Y es que la exaltación y salvaguardia de la identidad vecinal, a partir de cierto punto - el extremo en que fracasa el respeto mutuo ceremonialmente sugerido-, requiere, ya, de expeditivos métodos no ceremoniales, no ritualizados: la acción violenta de "veciños" solidariamente unidos contra "xente de fora". Es aquí donde la identidad de parro- 
quia alcanza un clímax expresivo y la solidaridad entre "veciños" se sitúa en la cima de la escala de valores. Pero, esta vez, por otras vías no ceremoniales ni poéticas.

El conjunto de niveles o estratos socio-espaciales que dan forma a la identidad comunitaria se articulan en un orden sistemático. Y tal sistematización es de un carácter doble y simultáneo: cognitivo y ético. Además, estos dos caracteres del sistema de la identidad comunitaria se interimplican recíprocamente: sólo desde el reconocimiento del trinomio nosotros/ vosotros/ellos es posible dinamizar procesos en los que se fijan y generan solidaridades y rivalidades o hermanamientos entre personas o entre grupos. Pero, inversamente, sólo a través de tales solidaridades/rivalidades o alianzas en expresiva operación emerge nítido, resaltando en sus fronteras y dotado de su existencia simbólica el mundo de la identidad comunitaria, de las formas contingentes, heterogéneas, opuestas y complementarias de "ser veciños". Y es en las escenificaciones festivas, en estos excepcionales esquemas que por convergencia y concentración simbólica resumen la visión del mundo local, donde percibimos que el cosmos de la identidad grupal y el orden ético tradicional son interreferentes.

Madrid, 27 de junio de 1988. 